\title{
Review Article \\ Regulation and Function of Syk Tyrosine Kinase in Mast Cell Signaling and Beyond
}

\author{
Rodrigo Orlandini de Castro ${ }^{1,2}$ \\ ${ }^{1}$ Receptors and Signal Transduction Section, Oral Infection and Immunity Branch, National Institute of Dental and Craniofacial \\ Research, National Institutes of Health, Bethesda, MD 20892, USA \\ ${ }^{2}$ Department of Cell and Molecular Biology and Pathogenic Bioagents, Faculade de Medicina de Ribeirão Preto, University of São Paulo, \\ Ribeirão Preto, SP 14049-900, Brazil \\ Correspondence should be addressed to Rodrigo Orlandini de Castro, orlandini.rodrigo@gmail.com
}

Received 29 December 2010; Accepted 23 February 2011

Academic Editor: Peter van der Geer

Copyright (C 2011 Rodrigo Orlandini de Castro. This is an open access article distributed under the Creative Commons Attribution License, which permits unrestricted use, distribution, and reproduction in any medium, provided the original work is properly cited.

\begin{abstract}
The protein tyrosine kinase Syk plays a critical role in FceRI signaling in mast cells. Binding of Syk to phosphorylated immunoreceptor tyrosine-based activation motifs (p-ITAM) of the receptor subunits results in conformational changes and tyrosine phosphorylation at multiple sites that leads to activation of Syk. The phosphorylated tyrosines throughout the molecule play an important role in the regulation of Syk-mediated signaling. Reconstitution of receptor-mediated signaling in Syk ${ }^{-/-}$cells by wild-type Syk or mutants which have substitution of these tyrosines with phenylalanine together with in vitro assays has been useful strategies to understand the regulation and function of Syk.
\end{abstract}

\section{Introduction}

The clustering of the high-affinity receptor for $\operatorname{IgE}(\mathrm{FccRI})$ initiates a series of biochemical events in mast cells or basophils that culminate with the release of preformed mediators from granules together with the synthesis and release of lipid mediators and cytokines [1-6]. The FceRI is a member of a larger family of multisubunit immune recognition receptors (MIRRs), which also includes the T-cell receptor (TCR), the B-cell receptor (BCR), and some other Fc receptors (FcR) like Fc $\gamma$ RI and Fc $\gamma$ RIII [7]. These receptors have no intrinsic catalytic activity. Instead, their activation results in phosphorylation of the two tyrosines in the ITAM (immunoreceptor tyrosine-based activation motif) within the cytoplasmic tails of subunits of the receptor. ITAM-based signaling shares a common signal transduction mechanism, where the recruitment and activation of Syk or ZAP-70 is a critical step for these immunoreceptors to activate these cells $[8,9]$. This paper summarizes important studies and new findings on regulation and function of Syk in mast cell signaling and some other cells.

\section{Syk-Mediated FcerI Activation}

FceRI is a tetrameric structure formed by the complex $\alpha \beta \gamma_{2}$ chains. The $\alpha$-subunit binds the Fc portion of $\operatorname{IgE}$ at a ratio of $1: 1$ while the $\beta$-subunit and the disulphide-linked $\gamma$ subunits contain ITAMs in their cytoplasmic tail $[5,10]$. Aggregation of FceRI results in phosphorylation of the tyrosines within the ITAMs by Lyn, or another member of the Src family of tyrosine kinases that associate with the receptor. Phosphorylated ITAM then serves as a docking site for Syk; this binding of Syk through its $\mathrm{SH} 2$ domains results in a conformational change of Syk which allows trans- and autophosphorylation of its catalytic domain, as well as phosphorylation by Lyn, thereby increasing Syk enzymatic activity $[2,11]$.

Tyrosine-phosphorylated Syk leads to downstream propagation of signaling with phosphorylation of linker for activation of T cells (LAT), Vav, BTK, phospholipase C $\gamma$ (PLC $\gamma$ ), and $\mathrm{SH} 2$ domain-containing leukocyte protein of $76 \mathrm{kDa}$ (SLP-76) [12, 13]. Phosphorylated LAT functions as a signal platform providing binding sites directly for growth factor receptor-bound protein 2 (Grb2), Grb2-related adaptor 
downstream of Shc (Gads), and PLC $\gamma$, while indirectly binding for SLP-76, NCK, and other adaptors. PLC $\gamma$ hydrolyzes phosphatidylinositol 4,5-bisphosphate $\left(\mathrm{PIP}_{2}\right)$ in the plasma membrane to produce diacylglycerol, which activates protein kinase C (PKC), and inositol 1,4,5-triphosphate $\left(\mathrm{IP}_{3}\right)$ [6, 14]. The binding of $\mathrm{IP}_{3}$ to its receptor in the endoplasmic reticulum (ER) membrane rapidly induces the first stage of calcium $\left(\mathrm{Ca}^{2+}\right)$ mobilization, which is the transient release of $\mathrm{Ca}^{2+}$ from ER stores. The depletion of calcium in the ER induces formation of multimers of Stimlin the ER membrane, which move and interact directly with Orail, a pore subunit of the $\mathrm{Ca}^{2+}$ channel, in the plasma membrane. Together with calcium released from ER, this induces prolonged $\mathrm{Ca}^{2+}$ influx through store-operated calcium releaseactivated calcium (CRAC) channels in the plasma membrane $[15,16]$. Syk-mediated tyrosine phosphorylation of BTK, SLP-76, LAT, and PLC $\gamma$ is essential to generate signals for sustained $\mathrm{Ca}^{2+}$ influx. All these events culminate with mast cell degranulation, phosphorylation of MAP kinases, and activation of nuclear factor for T-cell activation (NFAT) and nuclear factor $\kappa \mathrm{B}(\mathrm{NF} \kappa \mathrm{B})$, which turn on cytokine synthesis.

\section{The Syk Tyrosine Kinase}

Syk gene was first cloned on the basis of partial sequenced information of the $40 \mathrm{kDa}$ kinase from a porcine spleen. The product of this gene was described as a member of a new nonreceptor-type protein tyrosine kinase of $72 \mathrm{kDa}$ $\left(\mathrm{p} 72^{s y k}\right)$. Interestingly, unlike $s r c$ family protein kinases, $\mathrm{p} 72^{\text {syk }}$ has a second SH2 instead of an SH3 domain [17]. Molecular cloning then described a gene that encoded a $70 \mathrm{kDa}$ protein tyrosine kinase associated with the $\zeta$ chain of the T-cell receptor, termed ZAP-70 [18]. This also had two SH2 domains and was very similar to $\mathrm{p} 72^{\text {syk }}$. Those findings indicated that Syk and ZAP-70 belonged to a distinct subfamily of nonreceptor protein tyrosine kinases [19], named Syk family of protein kinases. Syk is expressed in mast cells, B cells, immature T cells, and platelets, whereas ZAP-70 is in T cells and natural killer cells $[18,20]$. Structurally, both Syk and ZAP-70 have two Src-homology 2 domains (SH2) and a kinase domain. The interdomain $\mathrm{A}$ is located between the $\mathrm{NH}_{2}$-terminal SH2 (SH2-N) and $\mathrm{COOH}$-terminal SH2 (SH2-C), while interdomain B or linker region is between the $\mathrm{SH} 2-\mathrm{C}$ and the kinase domains; following the kinase domain there is a short COOH-terminal extension (tail) [21] (Figure 1).

In vivo, Syk has been reported to be essential in maintaining vascular integrity and wound healing during embryogenesis. Syk ${ }^{-1-}$ mice showed petechiae, suffered severe hemorrhaging as embryos, and died perinatally [22, 23]. Also, irradiated mice reconstituted with Syk-deficient fetal liver showed a block in B-cell development and maturation [23].

In cells, Syk plays an essential role in IgE-mediated activation of mast cells. Syk ${ }^{-/-}$mast cells are unable to induce $\mathrm{Ca}^{2+}$ mobilization, degranulate, phosphorylate MAP kinases, and activate NFAT or NF $\kappa$ B; but transfection of these cells with Syk reconstitutes their activation [24-26]. Similarly, BCR crosslinking in Syk $\mathrm{S}^{-/-} \mathrm{B}$ cells also fails to induce cell activation [27]. Recent studies have shown that bone marrow-derived mast cell (BMMC) treated with siRNA targeted to Syk efficiently decreases receptor-induced cell activation $[2,28]$.

Due to structural similarities Syk and ZAP-70 have also some functional redundancies. For example, expression of either ZAP-70 or Syk reconstitutes receptor-induced cell activation in Syk-negative mast cells and B cells [26, 27, 29]; however, ZAP-70 but not Syk requires CD45 to efficiently induce FceRI-induced signaling responses in Syk-negative mast cells [29]. Additionally, in CD45-deficient T cells, Syk but not ZAP-70 restores the TCR signaling pathway [30]. CD45 is a critical component of TCR, acting as a positive regulator of Src family protein tyrosine kinases, such as Lck. Activation of TCR leads to dephosphorylation of negative sites of Lck which then activates ZAP-70. These studies demonstrate that binding of Syk to the phosphorylated ITAM is enough to trigger its enzymatic activity while ZAP-70 requires an additional stimulatory input from other tyrosine kinases.

\section{Phosphorylated ITAM-Induced Syk Activation}

ITAM-based signaling has been extensively characterized and serves as a model for receptor-mediated signal transduction $[8,9]$. The ITAM consensus sequence is $\mathrm{D} / \mathrm{E}-(\mathrm{X})_{2}-\mathrm{Y}-(\mathrm{X})_{2}-$ $\mathrm{L} / \mathrm{I}-(\mathrm{X})_{6 / 7}-\mathrm{Y}-(\mathrm{X})_{2}-\mathrm{L} / \mathrm{I}$, where the two tyrosines residues are phosphorylated upon receptor activation. The $\beta$ - and $\gamma$ subunits of FceRI complex contain ITAM on their cytoplasmic tails. Phosphorylated ITAM (p-ITAM) serves as the docking site for the two SH2 domains of Syk [31-34]. The association of Syk with p-ITAM occurs with an antiparallel binding orientation: the $\mathrm{SH} 2-\mathrm{N}$ of Syk binds to the $\mathrm{COOH}-$ terminal phosphotyrosine of the ITAM while the SH2$\mathrm{C}$ binds to the $\mathrm{NH}_{2}$-terminal phosphotyrosine $[31,32]$ (Figure 2). In vitro experiments using synthetic peptides corresponding to the $\beta$ - or $\gamma$-ITAM of FceRI showed that Syk binds preferentially to the biphosphorylated $\gamma$-ITAM [32]. The SH2 domain-mediated binding of Syk/ZAP-70 to phosphorylated ITAM in subunits of immune receptors is critical for activation of these cells; the expression in cells of truncated Syk containing just the two SH2 domains has a dominant-negative effect that inhibits binding of endogenous Syk and decreases receptor signaling [35]. Although both SH2 domains of Syk are required for its binding to p-ITAM, the SH2-C binds stronger to the phosphorylated $\gamma$-ITAM than the SH2-N. The binding of Syk to the pITAM results in conformational changes of Syk exposing its $\mathrm{COOH}$-terminal region [36] by disrupting the $\mathrm{COOH}$ terminal/SH2-interdomain interactions $[37,38]$. Interaction of the $\mathrm{COOH}$-terminal with $\mathrm{SH} 2$ interdomain stabilizes the autoinhibitory structure of the enzyme; the binding to p-ITAM induces a conformational change that "opens" the molecule resulting in Syk activation [25]. In addition, Syk itself can phosphorylate the ITAMs creating a positive feedback loop during the initial steps of receptor-mediated Syk activation [39] (Figure 2). 


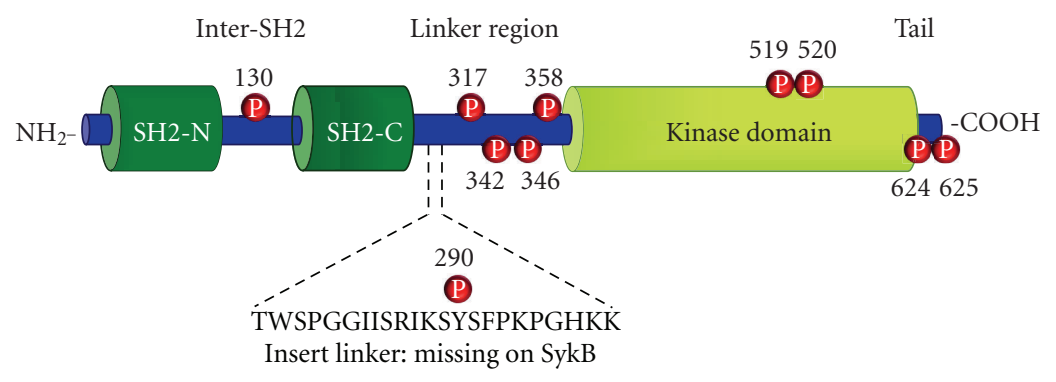

(a)

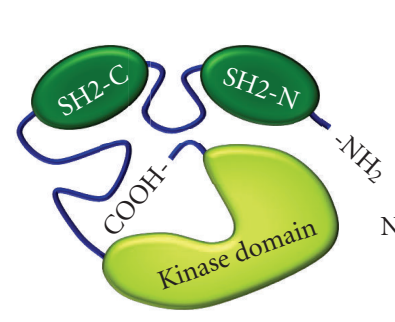

Autoinhibited

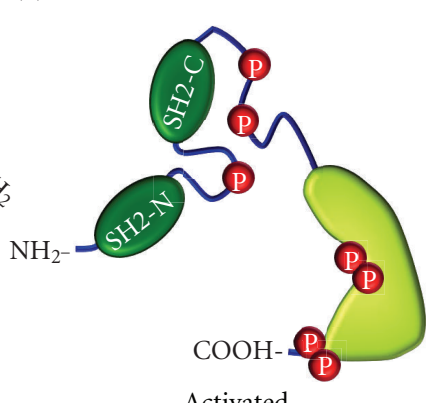

Activated

(b)

FIGURE 1: Structure of protein tyrosine kinase Syk: (a) a schematic diagram of the linear structure of Syk with the tyrosines marked that are phosphorylated after its in vitro activation. In the linker region there are 23 amino acids which are missing in SykB. (b) Suggested globular structure of autoinhibited (left) and activated (right) Syk with some phosphorylated tyrosines indicated.

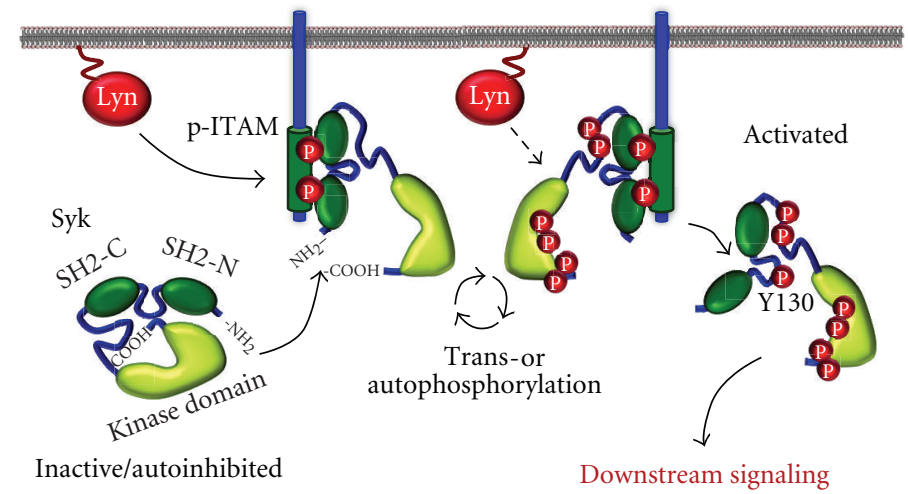

FIGURE 2: ITAM-based Syk activation: activation of the immunoreceptor, here represented by a $\gamma$-subunit of FceRI, results in the phosphorylation of the ITAMs by Lyn or other Src kinase that associates with the receptor. This recruits the cytoplasmic Syk which binds to the phosphorylated ITAM (p-ITAM) resulting in conformational changes that disrupt its autoinhibited structure, which increase the kinase activity of Syk. After activation, Syk is tyrosine phosphorylated essentially by trans- or autophosphorylation with some participation of other tyrosine kinases. The phosphorylation of Tyr-130 releases the kinase from the receptor allowing Syk to phosphorylate its targets in the cytoplasm of the cell.

\section{Autoinhibition of Syk/Zap-70}

Structural studies of ZAP-70 suggest an autoinhibitory state for Syk family kinases $[37,38]$. Several tyrosine residues throughout the molecule can regulate Syk/ZAP-70 enzymatic activity; phosphorylation of these can stabilize the active form, whereas in the nonphosphorylated state the same residues may contribute to autoinhibition of the enzyme. In the inactive ZAP-70, the hydrogen-bonding network is stabilized by a hydrophobic cluster formed by Pro-396, Tyr-397, and Tyr-474 in the kinase domain and Tyr-319 in the linker region, whereas, in the active form, the hydrogen-bonding network and hydrophobic interactions are disrupted [37]. This structural study of ZAP-70 was with a protein that had the $\mathrm{COOH}$-terminal region missing, and the crystal structure of only the SH2 domains of Syk has been determined. However, it is predicted that the two tyrosines in the tail of ZAP-70 interact with the $\alpha$-helix of the C-lobe of the kinase domain and the inter-SH2 domain regions; these interactions help to stabilize the autoinhibitory form of Syk/ZAP-70 $[25,38]$. 


\section{Regulation of Syk Function by Its Tyrosine Phosphorylation}

Activation of Syk leads to its tyrosine phosphorylation due mostly to autophosphorylation with some contribution by other tyrosine kinases [40]. Analysis of activated Syk has indentified ten tyrosines residues which are autophosphorylated in vitro [41] (Figure 1); several of these are also found phosphorylated in mast cells after receptor activation [42]. These phosphotyrosines can regulate Syk function and also generate potential docking sites for other molecules.

One of these phosphotyrosines at Tyr-130 is located in the inter-SH2 domain and is an early site of Syk autophosphorylation. Phosphorylation of Tyr-130 regulates the binding of Syk to the p-ITAM by dissociating Syk from the receptor. Substitution of Tyr-130 with Phe enhances binding of Syk to the receptor while this is greatly reduced by substitution with Glu $[43,44]$. Studies also suggest that phosphorylation of Tyr-130 destabilizes inter-SH2 domain structure, which alters the orientation and increases the distance between the two $\mathrm{SH} 2$ domains beyond the limit permitted for their functional binding to p-ITAM [44].

The linker region plays a critical role in regulation of Syk function. An alternative spliced form of Syk, named SykB, lacks 23 amino acids, known as "linker insert" in the linker region (Figure 1). This linker insert enhances the binding of Syk to the p-ITAM, which helps to explain why SykB is inefficient in reconstituting FceRI signaling in Syk-deficient mast cells [45]. Within the linker insert is Tyr-290, which is autophosphorylated in vitro [41]. Substitution of Tyr-290 of Syk with Phe does not affect Syk-mediated downstream signaling of either FceRI or TCR [45]. Also, BCR-mediated NFAT activation in Syk-deficient DT40 cells expressing SykY290F was similar to cells with wild-type Syk [46]. Therefore, Tyr-290 has no obvious effect on Syk-mediated signaling.

Three conserved tyrosines, Tyr-317, Tyr-342, and Tyr346 , are located in the linker region. These are found phosphorylated in both Syk and ZAP-70 after receptor activation $[42,47]$. It has been reported that Tyr-317 is a negative regulatory site of Syk function [48]. Substitution of Tyr-317 with Phe increases Syk kinase activity and its autophosphorylation capacity. In vivo, expression of Syk-Y317F enhances mast cell degranulation and phosphorylation of PLC $\gamma 1$ and PLC $\gamma 2$ without affecting its binding to the p-ITAM [48]. Also, expression of Syk-Y317F in DT40 B cells enhances BCRmediated activation of both transcription factors NFAT and Elk-1 [49]. Phosphorylation of Tyr-317 not only negatively regulates Syk function but also creates a binding site for protein ubiquitin ligases of $\mathrm{Cbl}$ family, which target receptors and tyrosine kinases [50]. Among the three members of Cbl family proteins two of them, $c-C b l$ and Cbl-b, are expressed in hematopoietic cells [51]. The absence of Cbl-b enhances mast cell degranulation, $\mathrm{Ca}^{2+}$ influx, and synthesis of cytokines such as TNF- $\alpha$ and IL-6 [52, 53]. These are mostly due to increased phosphorylation of both Syk and receptor phosphorylation in $\mathrm{Cbl-b^{-/ }}$ mast cells. Studies using $\mathrm{c}-\mathrm{Cbl}^{-/-}$mast cells show that $\mathrm{c}$-Cbl has more effect on phosphorylation of MAP kinases but does not affect Syk phosphorylation [53]. Therefore phosphorylation of Tyr-317 negatively regulates Syk function, and this also creates a binding site for Cbl-b which leads to ubiquitination and degradation of Syk.

Tyrosines 342 and 346 are phosphorylated after receptor activation in mast cells [54]. These tyrosines have been reported to be involved in the interaction of Syk with PLC $\gamma$ and Vav. Thus, in COS cells expression of Syk with both Tyr-342 and Tyr-346 mutated to Phe results in loss of interaction of Syk with PLC $\gamma$ [55]. Experiments using twohybrid system suggest that phosphorylated Tyr-342 of Syk is a binding site for VAV [56]. Functional analysis of each of these tyrosines shows that substitution of Tyr-346 with Phe impairs Syk-mediated phosphorylation of SLP-76, LAT, and PLC- $\gamma 2$, calcium mobilization, and mast cell degranulation [54]. This can be as a result of decreased kinase activity and reduced binding of mutated Syk to phosphorylated $\gamma$ ITAM. Interestingly, Tyr-346 substitution with Phe has minimal effects on receptor-mediated mast cell degranulation. Another tyrosine phosphorylated in the linker region is Tyr358. This is autophosphorylated in vitro [41]; but there have been no reports on the role of Tyr-358 in Syk function.

Aggregation of FceRI results in phosphorylation of two adjacent tyrosines in the activation loop of Syk kinase domain, Tyr-519/Tyr-520. Both of these are essential for Sykmediated receptor signaling in mast cells [57]. Tyr-519 has more impact on histamine release, while Tyr-520 is more involved in phosphorylation of PLC $\gamma 2$. However, in vitro experiments show that substitution of one or both of these activation loop tyrosines with Phe does not affect the kinase activity of Syk nor its binding to the p-ITAM [57]. Other studies demonstrate that the binding of mAb AA4, an antibody that recognizes a mast cell-specific ganglioside on the cell surface [58], results in the strong tyrosine phosphorylation of cellular proteins including Syk, but not histamine release or phosphorylation of the activation loop tyrosines [40]. It is suggested that phosphorylation of the activation loop tyrosines occurs mostly by auto-transphosphorylation with some participation of other tyrosine kinases in the initiation of the phosphorylation process $[40,59]$. Therefore, the phosphorylation of activation loop tyrosines is critical for Syk-mediated FceRI signaling in mast cells. Unlike Syk, mutation of Tyr-493, analogous to Tyr-520 of Syk, abrogates the in vitro kinase activity of ZAP-70 [60]. This disparity in the in vitro function of the activation loop tyrosines of Syk and ZAP-70 can be explained by differences in the enzymatic activity of both proteins. For example, the kinase activity of ZAP-70 but not Syk depends on the presence of Lck for its initial activation, and the enzymatic activity of Syk is at least 100 -fold greater than that of ZAP-70 [57, 60, 61].

The COOH-terminal region of Syk has three conserved tyrosines (Tyr-623, Tyr-624, and Tyr-625); the last two of which are also conserved in human ZAP-70 [25]. Tyr-624 and Tyr-625 are phosphorylated in both Syk and ZAP70 by in vitro autophosphorylation or following receptor stimulation $[41,42,62,63]$. Mutation of these three Tyr to Phe disrupts the autoinhibitory state of Syk which allows it to be more tyrosine phosphorylated by another tyrosine kinase in cells, which activates Syk and results in autophosphorylation [25]. Without such phosphorylation by another tyrosine 
kinase, these mutations result in Syk that has very low enzymatic activity and capacity for autophosphorylation. Therefore, mutation of these tyrosines results in Syk which functionally is more similar to ZAP-70 in its requirement for another tyrosine kinase for activation. In mast cells this mutated Syk is less efficient in FceRI signaling because of decreased binding to phosphorylated ITAM independent of phosphorylation of Tyr-130. Together with the decreased kinase activity, this leads to reduced mast cell degranulation, decreased phosphorylation of MAP kinases, and lower activation of NFAT and NF $\kappa$ B. Other results strongly suggest that phosphorylation of $\mathrm{COOH}$-terminal tyrosines of Syk creates a docking site for SLP-65 in B cells, although it is not clear if this is a result of direct binding or if other adaptors could mediate this interaction [63].

\section{Direct and Indirect Negative Regulation of Syk Signaling}

The regulation of Syk function also includes the downregulation of its activity after receptor activation; this process involves the participation of protein phosphatases and ubiquitin ligases. Cbl-b-mediated Syk ubiquitination and degradation has been the most characterized mechanism to downregulate Syk function in receptor signaling (previously discussed). The phosphatases SHIP1, SHP1, and SHP2 are tyrosine phosphorylated after FceRI aggregation, and this phosphorylation is independent of Syk. These phosphatases are found associated with FceRI in mast cells $[64,65]$. In vitro experiments show that both SHP1 and SHP2 dephosphorylate $\beta$ - and $\gamma$-subunits of the FceRI [65]. These phosphatases indirectly inhibit Syk function by limiting the intensity and duration of receptor phosphorylation which, as discussed above, leads to Syk activation. Recently, a novel histidine tyrosine phosphatase, T-cell ubiquitin ligand-2 (TULA-2), has been described to associate with Syk [66]. TULA2, also known as ubiquitin-associated domain and $\mathrm{SH} 3$ domain-containing protein $\mathrm{B}$ (UBASH3B) or suppressor of T-cell receptor signaling-1 (Sts-1), belongs to the TULAfamily of proteins $[67,68]$. It has been shown that TULA2 targets phosphotyrosines 317, 346, and 519/520 of Syk [69]. Additionally, Syk has increased phosphorylation in GPVI-stimulated platelets from TULA-deficient mice or by inhibiting TULA-2 activity in $293 \mathrm{~T}$ cells $[66,69,70]$. T cells from TULA ${ }^{-1-}$ mice are hyperresponsive to TCR stimulation as a result of increased activation of ZAP-70 [71]. These findings strongly suggest that TULA-2 is a phosphatase which directly downregulates the activity of Syk family proteins.

\section{Syk-Mediated Actin Redistribution in Mast Cells}

The RBL-2H3, a mast cell line, has been widely used as a model to study FceRI-mediated signaling. Morphological studies show that resting RBL-2H3 cells are normally spindle shaped with small microvilli on their surface; these cells become flattened and spread and their surfaces are ruffled and plicated after receptor activation [58]. These morphological changes involve redistribution of actin and are in parallel with mediator release. Some other experiments demonstrate that these morphological changes are downstream of Syk and are $\mathrm{Ca}^{2+}$ dependent $[2,72]$. For example, activation of FceRI induces minimal or no morphological change in RBL-2H3 $\mathrm{Syk}^{-/-}$variant mast cell line; but this is reconstituted by stable expression of Syk in these cells. Additionally, receptor-mediated redistribution of actin is observed only in cells expressing Syk after transient transfection of Syk ${ }^{-/-}$cells (Figure 3). Therefore, the cellular mechanisms which result in morphological changes in mast cells are dependent on Syk activation.

\section{New Studies on Syk Function}

Receptor-induced Syk tyrosine phosphorylation has been well characterized in hematopoietic cells $[2,12,13,38,73]$. However, there is little information on Syk being phosphorylated on Ser/Thr residues. Recently, an interesting study using phosphopeptide mapping and mass spectrometric analyses identified a new phosphorylated residue in the linker region of Syk, Ser-291 [46]. This is phosphorylated by PKC after BCR activation or PMA treatment in the Syk-deficient DT40 cells expressing Syk-EGFP. Substitution of Ser-291 with Ala decreases Syk-mediated BCR signaling to activate NFAT and Elk-1 but does not affect Syk kinase activity [46]. In ZAP70 , Ser-520 was predominantly phosphorylated in normal $\mathrm{T}$ lymphocytes and Jurkat T cells. Substitution of Ser-520 with Ala reduced the capacity of ZAP-70 to autophosphorylate and to mediate TCR-induced IL-2 promoter activation [74]. Recently, it was demonstrated that Ser-197 in the cytoplasmic tail of Ig- $\alpha$ is phosphorylated upon BCR activation which inhibits signaling [75]. Surprisingly, this study suggests that Syk is the kinase responsible for phosphorylating Ser197 of Ig- $\alpha$, indicating a dual-specificity kinase activity for Syk.

\section{Conclusion}

Studies have shown that Syk is a key player in mast cells and other hematopoietic cells. Several studies have also suggested the mechanisms that regulate Syk function based on its structure and phosphorylated tyrosines. Mutating Syk has been the strategy most frequently used to understand its function but, surprisingly, this could affect the autoinhibitory structure of the molecule resulting in secondary effects. For example, mutations of the three conserved tyrosines in the $\mathrm{COOH}$-terminal region of Syk decreases its binding capacity to the p-ITAM due to decreased autoinhibitory structure of mutated Syk and not because of the mutation itself [25]. Also, Syk carrying either a green fluorescence protein (GFP) domain or an affinity tag at the $\mathrm{NH}_{2}$ - or $\mathrm{COOH}$-terminal seems to be more active than wild-type Syk $[38,63]$. This could result in some nonspecific activities of the molecule when expressed in cells. Understanding Syk function and 


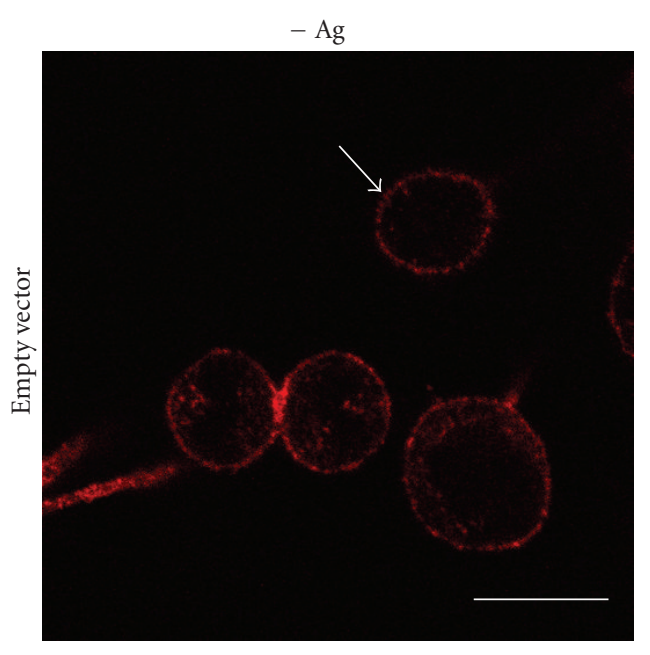

(a)

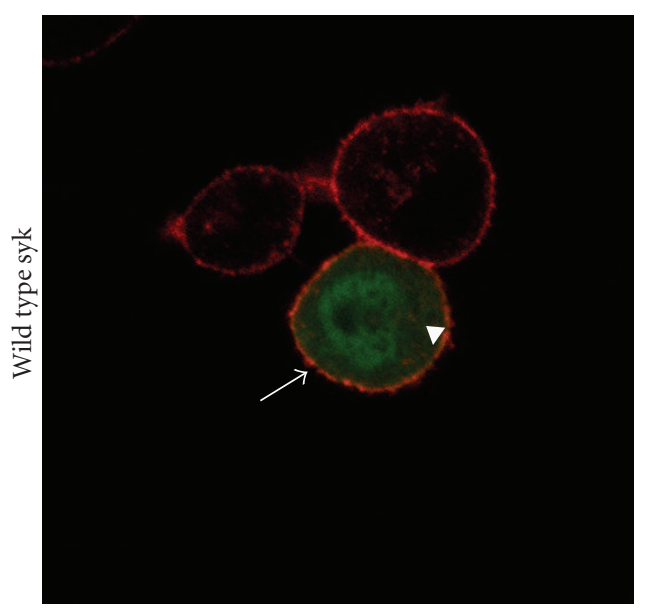

(c)

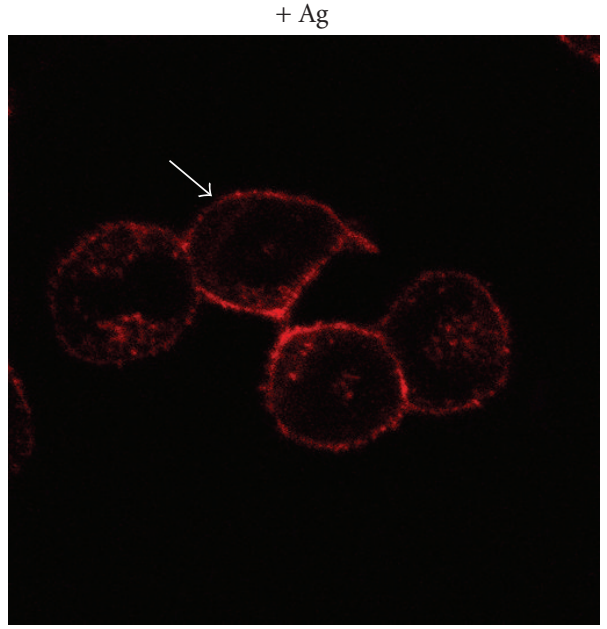

(b)

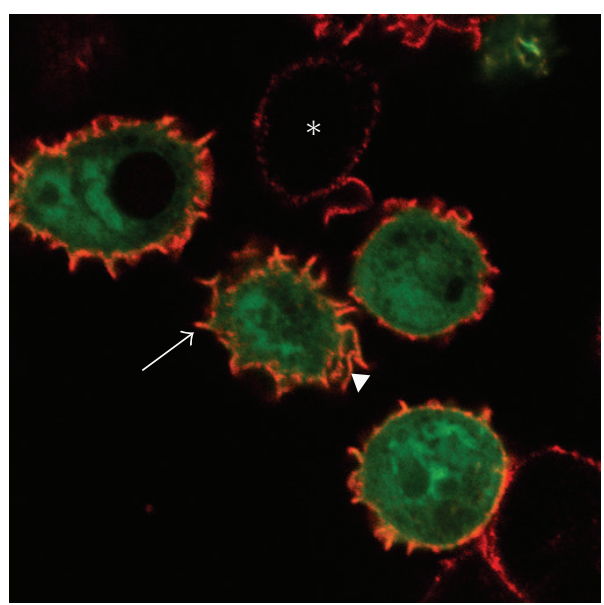

(d)

FIGURE 3: Reconstitution of Syk-mediated actin redistribution in Syk-/- mast cells: C4A2 Syk-/- mast cells were transfected with empty plasmids or plasmids that express wild-type Syk [25]. These cells were cultured with antigen-specific IgE, washed, and then either incubated with medium alone ( (a) and (c)) or medium containing antigen. After $10 \mathrm{~min}$, the cells were immunostained as described previously [76] using $\mathrm{mAb}$ anti-Syk (26B61A6) and $\mathrm{F}\left(\mathrm{ab}^{\prime}\right)_{2}$ donkey antimouse IgG conjugated with Alexa 488; actin staining was with phalloidin conjugated with Alexa-633. In nonactivated Syk-/ - cells transfected with empty vector (a) or wild-type Syk (c), actin was uniformly distributed on the cell periphery (arrow). After receptor activation, in these cells expressing wild-type Syk ( $(\mathrm{d})$, arrow), there was redistribution of actin which follows the ruffled cell membrane, characteristic of activated mast cells; while minimal or no redistribution of actin was observed in cells that did not express Syk ((d), asterisk) or in cells transfected with empty vector (b). In nonstimulated cells expressing wild-type Syk, the Syk was found throughout the cytoplasm ((c), arrow head); after receptor activation, part of the cytoplasmic Syk was recruited to the plasma membrane and colocalized with actin ((d), arrow head). Bar: $10 \mu \mathrm{m}$.

its interactions is important for developing pharmacological compounds that regulate its function.

\section{Acknowledgments}

This paper was supported in part by the Intramural Research Program of NIH/NIDCR. The author thanks Dr. Reuben P. Siraganian, Dr. Emilia Alina Barbu, and Dr. Juan Zhang for helpful discussions and review of this paper.

\section{References}

[1] H. Turner and J. P. Kinet, "Signalling through the high-affinity IgE receptor FceRI,” Nature, vol. 402, no. 6760, pp. B24-B30, 1999.

[2] R. P. Siraganian, R. O. de Castro, E. A. Barbu, and J. Zhang, "Mast cell signaling: the role of protein tyrosine Kinase Syk, its activation and screening methods for new pathway participants," FEBS Letters, vol. 584, no. 24, pp. 4933-4940, 2010. 
[3] J. Kalesnikoff and S. J. Galli, "New developments in mast cell biology," Nature Immunology, vol. 9, no. 11, pp. 1215-1223, 2008.

[4] D. Alvarez-Errico, E. Lessmann, and J. Rivera, "Adapters in the organization of mast cell signaling," Immunological Reviews, vol. 232, no. 1, pp. 195-217, 2009.

[5] R. P. Siraganian, "Mast cell signal transduction from the highaffinity IgE receptor," Current Opinion in Immunology, vol. 15, no. 6, pp. 639-646, 2003.

[6] A. M. Gilfillan and C. Tkaczyk, "Integrated signalling pathways for mast-cell activation," Nature Reviews Immunology, vol. 6, no. 3, pp. 218-230, 2006.

[7] J. C. Cambier, "Antigen and Fc receptor signaling the awesome power of the immunoreceptor tyrosine-based activation motif (ITAM)," Journal of Immunology, vol. 155, no. 7, pp. 32813285, 1995.

[8] D. M. Underhill and H. S. Goodridge, "The many faces of ITAMs," Trends in Immunology, vol. 28, no. 2, pp. 66-73, 2007.

[9] S. Fodor, Z. Jakus, and A. Mócsai, "ITAM-based signaling beyond the adaptive immune response," Immunology Letters, vol. 104, no. 1-2, pp. 29-37, 2006.

[10] M. B. Keown, A. J. Henry, R. Ghirlando, B. J. Sutton, and H. J. Gould, "Thermodynamics of the interaction of human immunoglobulin E with its high-affinity receptor FceRI," Biochemistry, vol. 37, no. 25, pp. 8863-8869, 1998.

[11] A. M. Scharenberg, S. Lin, B. Cuenod, H. Yamamura, and J. P. Kinet, "Reconstitution of interactions between tyrosine Kinases and the high affinity IgE receptor which are controlled by receptor clustering," The EMBO Journal, vol. 14, no. 14, pp. 3385-3394, 1995.

[12] A. Mócsai, J. Ruland, and V. L. J. Tybulewicz, "The SYK tyrosine Kinase: a crucial player in diverse biological functions," Nature Reviews Immunology, vol. 10, no. 6, pp. 387-402, 2010.

[13] K. Sada, T. Takano, S. Yanagi, and H. Yamamura, "Structure and function of Syk protein-tyrosine Kinase," Journal of Biochemistry, vol. 130, no. 2, pp. 177-186, 2001.

[14] J. Rivera, N. A. Fierro, A. Olivera, and R. Suzuki, "Chapter 3 new insights on mast cell activation via the High affinity receptor for IgE," Advances in Immunology, vol. 98, pp. 85-120, 2008.

[15] P. G. Hogan, R. S. Lewis, and A. Rao, "Molecular basis of calcium signaling in lymphocytes: STIM and ORAI," Annual Review of Immunology, vol. 28, pp. 491-533, 2010.

[16] M. Vig and J. P. Kinet, "Calcium signaling in immune cells," Nature Immunology, vol. 10, no. 1, pp. 21-27, 2009.

[17] T. Taniguchi, T. Kobayashi, J. Kondo et al., "Molecular cloning of a porcine gene syk that encodes a $72-\mathrm{kDa}$ protein-tyrosine Kinase showing high susceptibility to proteolysis," The Journal of Biological Chemistry, vol. 266, no. 24, pp. 15790-15796, 1991.

[18] A. C. Chan, M. Iwashima, C. W. Turck, and A. Weiss, "ZAP-70: a $70 \mathrm{kd}$ protein-tyrosine Kinase that associates with the TCR $\zeta$ chain," Cell, vol. 71, no. 4, pp. 649-662, 1992.

[19] C. Yang, S. Yanagi, X. Wang, K. Sakai, T. Taniguchi, and H. Yamamura, "Purification and characterization of a proteintyrosine Kinase p72(syk) from porcine spleen," European Journal of Biochemistry, vol. 221, no. 3, pp. 973-978, 1994.

[20] A. C. Chan, N. S. C. van Oers, A. Tran et al., "Differential expression of ZAP-70 and Syk protein tyrosine Kinases, and the role of this family of protein tyrosine Kinases in TCR signaling," Journal of Immunology, vol. 152, no. 10, pp. 47584766, 1994.
[21] R. P. Siraganian, J. Zhang, K. Suzuki, and K. Sada, "Protein tyrosine Kinase Syk in mast cell signaling," Molecular Immunology, vol. 38, no. 16-18, pp. 1229-1233, 2002.

[22] A. M. Cheng, B. Rowley, W. Pao, A. Hayday, J. B. Bolen, and T. Pawson, "Syk tyrosine Kinase required for mouse viability and B-cell development," Nature, vol. 378, no. 6554, pp. 303-306, 1995.

[23] M. Turner, P. J. Mee, P. S. Costello et al., "Perinatal lethality and blocked B-cell development in mice lacking the tyrosine Kinase Syk," Nature, vol. 378, no. 6554, pp. 298-302, 1995.

[24] A. C. G. Grodzki, K. D. Moon, E. H. Berenstein, and R. P. Siraganian, "FceRI-induced activation by low antigen concentrations results in nuclear signals in the absence of degranulation," Molecular Immunology, vol. 46, no. 13, pp. 2539-2547, 2009.

[25] R. O. de Castro, J. Zhang, M. C. Jamur, C. Oliver, and R. P. Siraganian, "Tyrosines in the carboxyl terminus regulate Syk Kinase activity and function," The Journal of Biological Chemistry, vol. 285, no. 34, pp. 26674-26684, 2010.

[26] J. Zhang, E. H. Berenstein, R. L. Evans, and R. P. Siraganian, "Transfection of Syk protein tyrosine Kinase reconstitutes high affinity IgE receptor-mediated degranulation in a Syk-negative variant of rat basophilic leukemia RBL-2H3 cells," Journal of Experimental Medicine, vol. 184, no. 1, pp. 71-79, 1996.

[27] G. H. Kong, J. Y. Bu, T. Kurosaki, A. S. Shaw, and A. C. Chan, "Reconstitution of Syk function by the ZAP-70 protein tyrosine Kinase," Immunity, vol. 2, no. 5, pp. 485-492, 1995.

[28] E. A. Barbu, J. Zhang, and R. P. Siraganian, "The limited contribution of Fyn and Gab2 to the high affinity IgE receptor signaling in mast cells," The Journal of Biological Chemistry, vol. 285, no. 21, pp. 15761-15768, 2010.

[29] J. Zhang and R. P. Siraganian, "CD45 is essential for FceRI signaling by ZAP70, but not Syk, in Syk- negative mast cells," Journal of Immunology, vol. 163, no. 5, pp. 2508-2516, 1999.

[30] D. H. Chu, H. Spits, J. F. Peyron, R. B. Rowley, J. B. Bolen, and A. Weiss, "The Syk protein tyrosine Kinase can function independently of CD45 or Lck in T cell antigen receptor signaling," The EMBO Journal, vol. 15, no. 22, pp. 6251-6261, 1996.

[31] T. Chen, B. Repetto, R. Chizzonite et al., "Interaction of phosphorylated FceRI $\gamma$ immunoglobulin receptor tyrosine activation motif-based peptides with dual and single $\mathrm{SH} 2$ domains of p72(syk). Assessment of binding parameters and real time binding kinetics," The Journal of Biological Chemistry, vol. 271, no. 41, pp. 25308-25315, 1996.

[32] T. Kimura, H. Kihara, S. Bhattacharyya, H. Sakamoto, E. Appella, and R. P. Siraganian, "Downstream signaling molecules bind to different phosphorylated immunoreceptor tyrosine-based activation motif (ITAM) peptides of the high affinity IgE receptor," The Journal of Biological Chemistry, vol. 271, no. 44, pp. 27962-27968, 1996.

[33] L. Shiue, M. J. Zoller, and J. S. Brugge, "Syk is activated by phosphotyrosine-containing peptides representing the tyrosine-based activation motifs of the high affinity receptor for IgE," The Journal of Biological Chemistry, vol. 270, no. 18, pp. 10498-10502, 1995.

[34] H. Kihara and R. P. Siraganian, "Src homology 2 domains of Syk and Lyn bind to tyrosine-phosphorylated subunits of the high affinity IgE receptor," The Journal of Biological Chemistry, vol. 269, no. 35, pp. 22427-22432, 1994.

[35] J. A. Taylor, J. L. Karas, M. K. Ram, O. M. Green, and C. SeidelDugan, "Activation of the high-affinity immunoglobulin E receptor FceRI in RBL- $2 \mathrm{H} 3$ cells is inhibited by Syk $\mathrm{SH} 2$ 
domains," Molecular and Cellular Biology, vol. 15, no. 8, pp. 4149-4157, 1995.

[36] T. Kimura, H. Sakamoto, E. Appella, and R. P. Siraganian, "Conformational changes induced in the protein tyrosine Kinase p72 by tyrosine phosphorylation or by binding of phosphorylated immunoreceptor tyrosine-based activation motif peptides," Molecular and Cellular Biology, vol. 16, no. 4, pp. 1471-1478, 1996.

[37] S. Deindl, T. A. Kadlecek, T. Brdicka, X. Cao, A. Weiss, and J. Kuriyan, "Structural basis for the inhibition of tyrosine Kinase activity of ZAP-70," Cell, vol. 129, no. 4, pp. 735-746, 2007.

[38] Y. Kulathu, G. Grothe, and M. Reth, "Autoinhibition and adapter function of Syk," Immunological Reviews, vol. 232, no. 1, pp. 286-299, 2009.

[39] V. Rolli, M. Gallwitz, T. Wossning et al., "Amplification of $\mathrm{B}$ cell antigen receptor signaling by a Syk/ITAM positive feedback loop," Molecular Cell, vol. 10, no. 5, pp. 1057-1069, 2002.

[40] J. Zhang, M. L. Billingsley, R. L. Kincaid, and R. P. Siraganian, "Phosphorylation of Syk activation loop tyrosines is essential Syk function: an in vivo study using a specific anti-Syk activation loop phosphotyrosine antibody," The Journal of Biological Chemistry, vol. 275, no. 45, pp. 35442-35447, 2000.

[41] M. T. Furlong, A. M. Mahrenholz, K. I. H. Kim, C. L. Ashendel, M. L. Harrison, and R. L. Geahlen, "Identification of the major site of autophosphorylation of the murine protein-tyrosine Kinase Syk," Biochimica et Biophysica Acta, vol. 1355, no. 2, pp. 177-190, 1997.

[42] L. Cao, K. Yu, C. Banh et al., "Quantitative time-resolved phosphoproteomic analysis of mast cell signaling," Journal of Immunology, vol. 179, no. 9, pp. 5864-5876, 2007.

[43] L. M. Keshvara, C. Isaacson, M. L. Harrison, and R. L. Geahlen, "Syk activation and dissociation from the B-cell antigen receptor is mediated by phosphorylation of tyrosine 130," The Journal of Biological Chemistry, vol. 272, no. 16, pp. 10377-10381, 1997.

[44] Y. Zhang, H. Oh, R. A. Burton, J. W. Burgner, R. L. Geahlen, and C. B. Post, “Tyr130 phosphorylation triggers Syk release from antigen receptor by long-distance conformational uncoupling," Proceedings of the National Academy of Sciences of the United States of America, vol. 105, no. 33, pp. 11760-11765, 2008.

[45] S. Latour, J. Zhang, R. P. Siraganian, and A. Veillette, "A unique insert in the linker domain of Syk is necessary for its function in immunoreceptor signalling," The EMBO Journal, vol. 17, no. 9, pp. 2584-2595, 1998.

[46] L. L. Paris, J. Hu, J. Galan et al., "Regulation of Syk by phosphorylation on serine in the linker insert," The Journal of Biological Chemistry, vol. 285, no. 51, pp. 39844-39854, 2010.

[47] J. D. Watts, M. Affolter, D. L. Krebs, R. L. Wange, L. E. Samelson, and R. Aebersold, "Identification by electrospray ionization mass spectrometry of the sites of tyrosine phosphorylation induced in activated Jurkat $\mathrm{T}$ cells on the protein tyrosine Kinase ZAP-70," The Journal of Biological Chemistry, vol. 269, no. 47, pp. 29520-29529, 1994.

[48] K. Sada, J. Zhang, and R. P. Siraganian, "Point mutation of a tyrosine in the linker region of Syk results in a gain of function," Journal of Immunology, vol. 164, no. 1, pp. 338-344, 2000.

[49] T. M. Yankee, L. M. Keshvara, S. Sawasdikosol, M. L. Harrison, and R. L. Geahlen, "Inhibition of signaling through the B cell antigen receptor by the protooncogene product, $\mathrm{c}-\mathrm{Cbl}$, requires Syk tyrosine 317 and the c-Cbl phosphotyrosinebinding domain," Journal of Immunology, vol. 163, no. 11, pp. 5827-5835, 1999.

[50] C. B. F. Thien and W. Y. Langdon, "c-Cbl and Cbl-b ubiquitin ligases: substrate diversity and the negative regulation of signalling responses," Biochemical Journal, vol. 391, no. 2, pp. 153-166, 2005.

[51] N. Rao, I. Dodge, and H. Band, "The Cbl family of ubiquitin ligases: critical negative regulators of tyrosine Kinase signaling in the immune system," Journal of Leukocyte Biology, vol. 71, no. 5, pp. 753-763, 2002.

[52] S. E. Gustin, C. B. F. Thien, and W. Y. Langdon, "Cbl-b is a negative regulator of inflammatory cytokines produced by IgE-activated mast cells," Journal of Immunology, vol. 177, no. 9, pp. 5980-5989, 2006.

[53] J. Zhang, Y. J. Chiang, R. J. Hodes, and R. P. Siraganian, "Inactivation of c-Cbl or Cbl-b differentially affects signaling from the high affinity IgE receptor," Journal of Immunology, vol. 173, no. 3, pp. 1811-1818, 2004.

[54] J. Zhang, E. Berenstein, and R. P. Siraganian, "Phosphorylation of Tyr342 in the linker region of Syk is critical for FceRI signaling in mast cells," Molecular and Cellular Biology, vol. 22, no. 23, pp. 8144-8154, 2002.

[55] C. L. Law, K. A. Chandran, S. P. Sidorenko, and E. A. Clark, "Phospholipase C- $\gamma 1$ interacts with conserved phosphotyrosyl residues in the linker region of Syk and is a substrate for Syk," Molecular and Cellular Biology, vol. 16, no. 4, pp. 1305-1315, 1996.

[56] M. Deckert, S. Tartare-Deckert, C. Couture, T. Mustelin, and A. Altman, "Functional and physical interactions of Syk family Kinases with the Vav proto-oncogene product," Immunity, vol. 5, no. 6, pp. 591-604, 1996.

[57] J. Zhang, T. Kimura, and R. P. Siraganian, "Mutations in the activation loop tyrosines of protein tyrosine Kinase Syk abrogate intracellular signaling but not Kinase activity," Journal of Immunology, vol. 161, no. 8, pp. 4366-4374, 1998.

[58] C. Oliver, N. Sahara, S. Kitani, A. R. Robbins, L. M. Mertz, and R. P. Siraganian, "Binding of monoclonal antibody AA4 to gangliosides on rat basophilic leukemia cells produces changes similar to those seen with Fce receptor activation," Journal of Cell Biology, vol. 116, no. 3, pp. 635-646, 1992.

[59] O. El-Hillal, T. Kurosaki, H. Yamamura, J. P. Kinet, and A. M. Scharenberg, "syk Kinase activation by a src Kinase-initiated activation loop phosphorylation chain reaction," Proceedings of the National Academy of Sciences of the United States of America, vol. 94, no. 5, pp. 1919-1924, 1997.

[60] A. C. Chan, M. Dalton, R. Johnson et al., "Activation of ZAP-70 Kinase activity by phosphorylation of tyrosine 493 is required for lymphocyte antigen receptor function," The EMBO Journal, vol. 14, no. 11, pp. 2499-2508, 1995.

[61] S. Latour, L. M. L. Chow, and A. Veillette, "Differential intrinsic enzymatic activity of Syk and Zap-70 proteintyrosine Kinases," The Journal of Biological Chemistry, vol. 271, no. 37, pp. 22782-22790, 1996.

[62] L. Zeitlmann, T. Knorr, M. Knoll, C. Romeo, P. Sirim, and W. Kolanus, "T cell activation induced by novel gain-offunction mutants of Syk and ZAP-70," The Journal of Biological Chemistry, vol. 273, no. 25, pp. 15445-15452, 1998.

[63] Y. Kulathu, E. Hobeika, G. Turchinovich, and M. Reth, "The Kinase Syk as an adaptor controlling sustained calcium signalling and B-cell development," The EMBO Journal, vol. 27, no. 9, pp. 1333-1344, 2008. 
[64] T. Kimura, H. Sakamoto, E. Appella, and R. P. Siraganian, "The negative signaling molecule $\mathrm{SH} 2$ domain-containing inositol- polyphosphate 5-phosphatase (SHIP) binds to the tyrosine-phosphorylated $\beta$ subunit of the high affinity $\operatorname{IgE}$ receptor," The Journal of Biological Chemistry, vol. 272, no. 21, pp. 13991-13996, 1997.

[65] T. Kimura, J. Zhang, K. Sagawa, K. Sakaguchi, E. Appella, and R. P. Siraganian, "Syk-Independent Tyrosine Phosphorylation and Association of the Protein Tyrosine Phosphatases SHP-1 and SHP-2 with the High Affinity IgE Receptor," Journal of Immunology, vol. 159, no. 9, pp. 4426-4434, 1997.

[66] D. H. Thomas, T. M. Getz, T. N. Newman et al., "A novel histidine tyrosine phosphatase, TULA-2, associates with Syk and negatively regulates GPVI signaling in platelets," Blood, vol. 116, no. 14, pp. 2570-2578, 2010.

[67] A. Y. Tsygankov, "Multidomain STS/TULA proteins are novel cellular regulators," IUBMB Life, vol. 60, no. 4, pp. 224-231, 2008.

[68] A. Y. Tsygankov, "TULA-family proteins: an odd couple," Cellular and Molecular Life Sciences, vol. 66, no. 17, pp. 29492952, 2009.

[69] X. Chen, L. Ren, S. Kim et al., "Determination of the substrate specificity of protein-tyrosine phosphatase TULA-2 and identification of Syk as a TULA-2 substrate," The Journal of Biological Chemistry, vol. 285, no. 41, pp. 31268-31276, 2010.

[70] R. Agrawal, N. Carpino, and A. Tsygankov, "TULA proteins regulate activity of the protein tyrosine Kinase Syk," Journal of Cellular Biochemistry, vol. 104, no. 3, pp. 953-964, 2008.

[71] N. Carpino, S. Turner, D. Mekala et al., "Regulation of ZAP-70 Activation and TCR Signaling by Two Related Proteins, Sts-1 and Sts-2," Immunity, vol. 20, no. 1, pp. 37-46, 2004.

[72] N. Sahara, R. P. Siraganian, and C. Oliver, "Morphological changes induced by the calcium ionophore A23187 in rat basophilic leukemia (2H3) cells," Journal of Histochemistry and Cytochemistry, vol. 38, no. 7, pp. 975-983, 1990.

[73] R. L. Geahlen, "Syk and pTyr'd: signaling through the B cell antigen receptor," Biochimica et Biophysica Acta, vol. 1793, no. 7, pp. 1115-1127, 2009.

[74] Y. Yang, P. Villain, T. Mustelin, and C. Couture, "Critical role of ser-520 phosphorylation for membrane recruitment and activation of the ZAP-70 tyrosine Kinase in T cells," Molecular and Cellular Biology, vol. 23, no. 21, pp. 7667-7677, 2003.

[75] B. Heizmann, M. Reth, and S. Infantino, "Syk is a dualspecificity Kinase that self-regulates the signal output from the B-cell antigen receptor," Proceedings of the National Academy of Sciences of the United States of America, vol. 107, no. 43, pp. 18563-18568, 2010.

[76] A. M. M. Silveira e Souza, E. S. Trindade, M. C. Jamur, and C. Oliver, "Gangliosides are important for the preservation of the structure and organization of RBL-2H3 mast cells," Journal of Histochemistry and Cytochemistry, vol. 58, no. 1, pp. 83-93, 2010. 

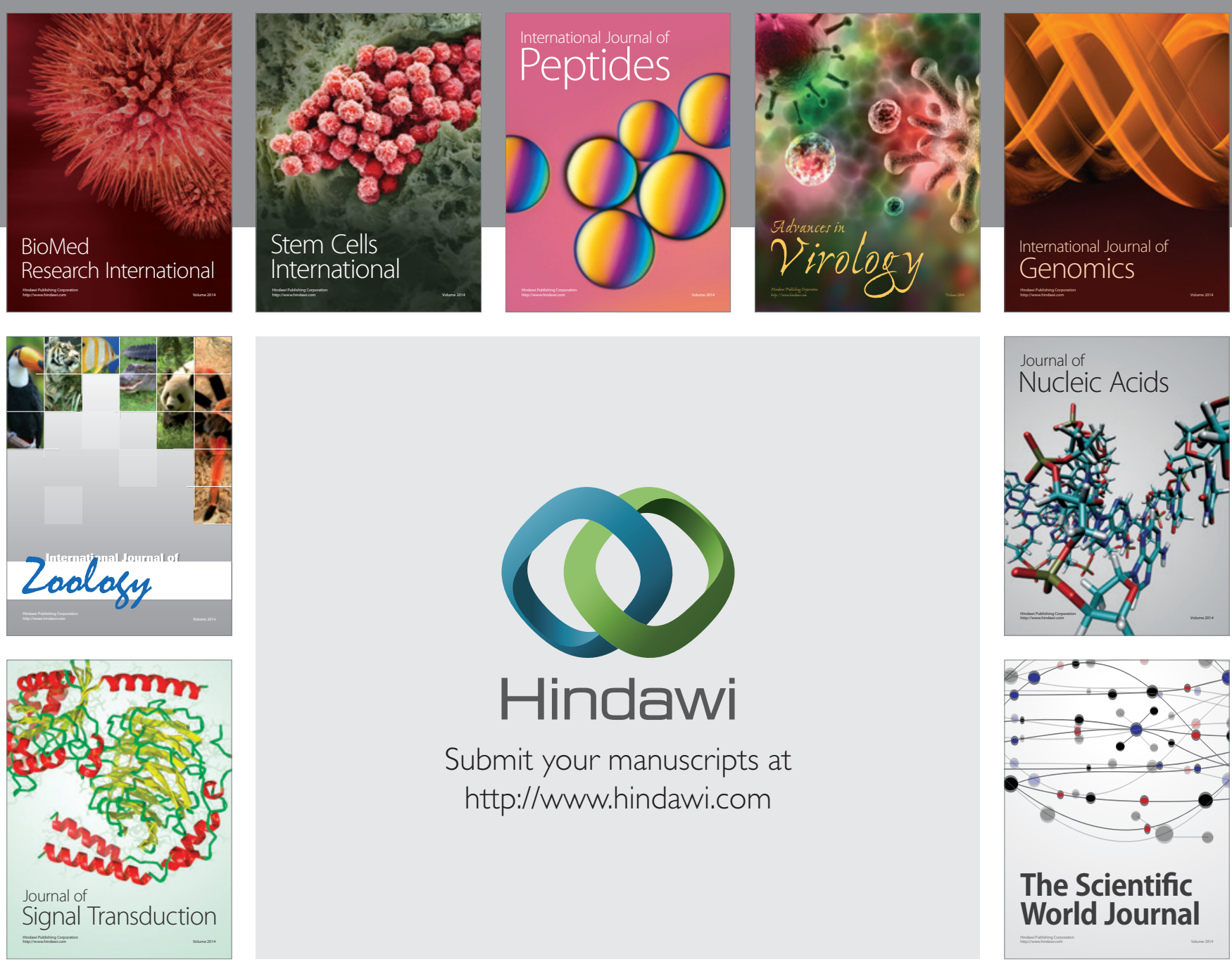

Submit your manuscripts at

http://www.hindawi.com
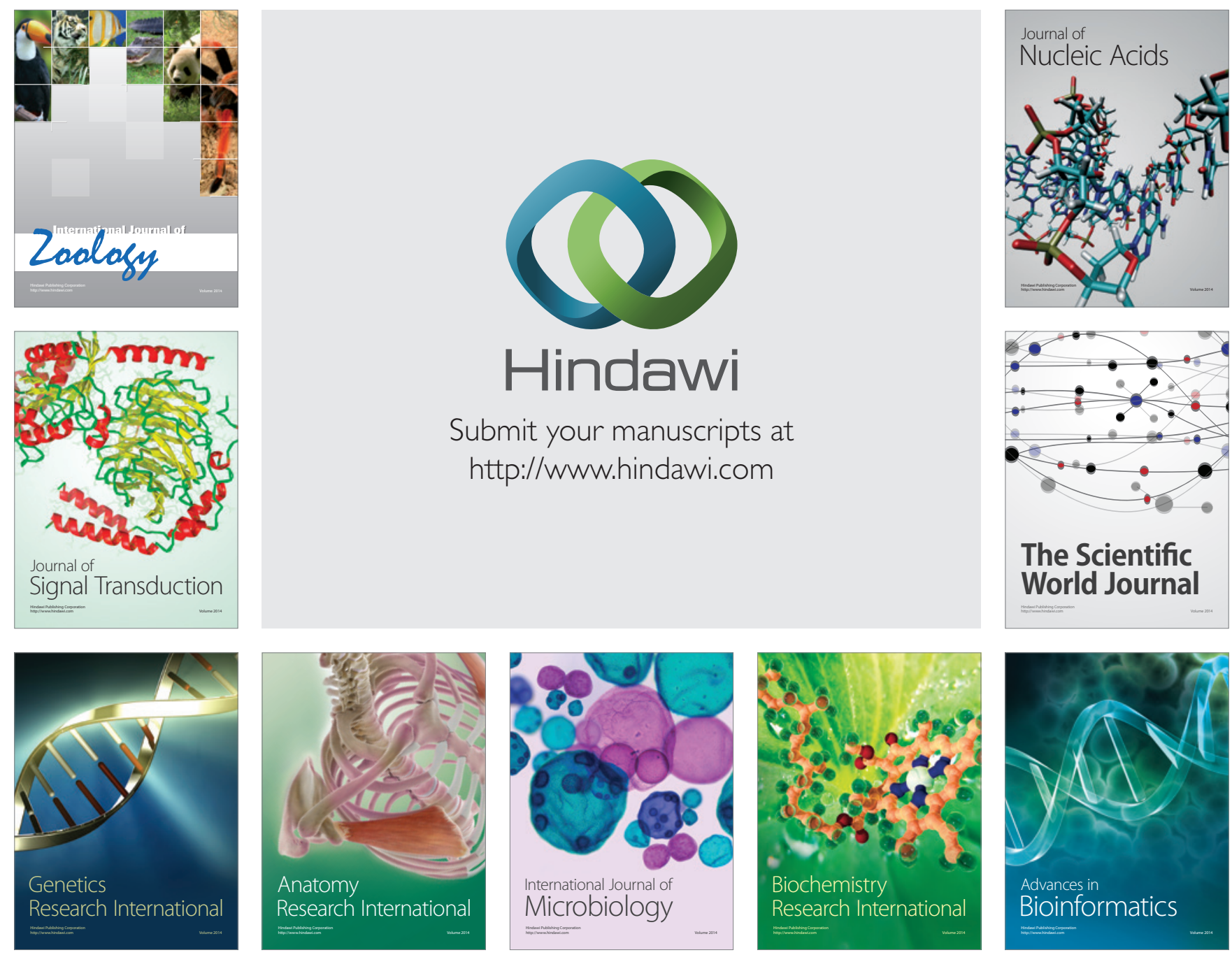

The Scientific World Journal
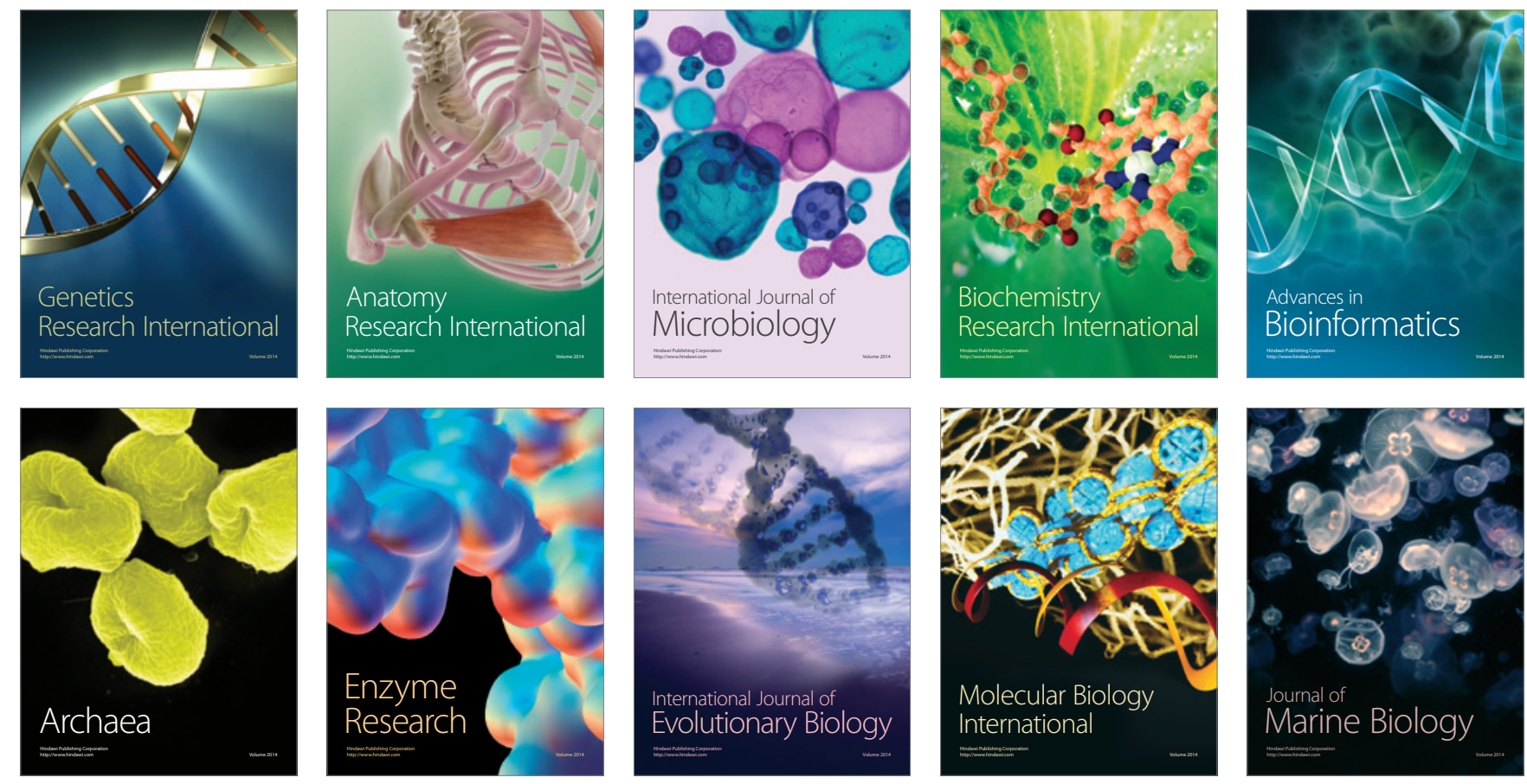